\title{
Preparation and Characterization of Microcapsule Filled with Ethyl Phenyl Acetate and Its Self-healing Application
}

\author{
Wanpeng $\mathrm{Ma}^{1, \mathrm{a}}$, Wei Zhang ${ }^{1, \mathrm{~b}}$, Yang Zhao ${ }^{1, \mathrm{c}}$, and Sijie Wang ${ }^{1, \mathrm{~d}}$ \\ ${ }^{1}$ Science and Technology on Remanufacturing Laboratory, Academy of \\ Armored Forces Engineering, Beijing 100072, China. \\ amawp010@126.com, 'zhangwei18@hotmail.com, 'zhaoyang033@163.com, 'wsj665588@126.co
}

$\mathrm{m}$

Keywords: Self-healing material, Microcapsule, Solvent, Ethyl phenyl acetate.

\begin{abstract}
Inspired by biological systems, self-healing materials were achieved by incorporating microcapsules into matrix. Urea-formaldehyde microcapsules filled with EPA were prepared by in situ polymerization method. Surface morphology, size distribution, chemical structure, and thermal analysis of microcapsules were analyzed. Self-healing composites were prepared by adding microcapsules to epoxy resin. Results show that healing efficiency was dependent on the microcapsule concentration. Fracture toughness could be fully restored when the microcapsule concentration was $10 \%$. Finally, microcapsules can be raptured by crack and solvents were release to crack region confirmed by SEM.
\end{abstract}

\section{Introduction}

Inspired by biological system, self-healing materials that can detect and heal the damage automatically have been developed [1]. To date, self-healing systems can be divided into two kinds according to healing methods: intrinsic self-healing systems and extrinsic self-healing systems. Intrinsic self-healing systems can be accomplished through reversible dynamic bond, hydrogen bonding, and molecular diffusion. Extrinsic self-healing systems use healing agent, which loaded in the microcapsule or microvascular, to bond the microcrack. Small spherical microcapsules enable healing agent to be dispersed throughout matrix easily, and then releases healing agent to the crack triggered by the mechanical stimulus and bond the crack. Many materials can be used as healing agents, such as dicyclopentadiene [2], epoxy resins [3, 4], solvents [5, 6] and so on. Caruso proposes solvent such as chlorobenzene, phenyl acetate ethyl or phenylacetate as healing agent, and healing mechanism involves solvent-induced swelling and polymeric chain entanglement. Compared with other healing systems, solvent-promoted self-healing systems are one-component, less expensive and high efficiency owing to elimination the problem caused by catalyst and harder.

In this study, ethyl phenyl acetate (EPA) was selected as a healing agent. Urea-formaldehyde microcapsules filled with EPA were synthesized using in-situ polymerization procedure. Surface morphology, size distribution, chemical structure, and thermal analysis of microcapsules were analyzed. The self-healing materials were prepared by incorporating microcapsules filled with EPA into the epoxy resins. Effects of microcapsule concentration on in situ efficiency were investigated.

\section{Materials and methods}

Microcapsule preparation. Microcapsules were prepared by in situ polymerization method $[7,8]$. 1.25 g EMA was mixed with $50 \mathrm{ml}$ deionized water in a warm bath to obtain surfactant solution. Then $200 \mathrm{ml}$ deionized water and $50 \mathrm{ml}$ aqueous solution of EMA were mixed in a $500 \mathrm{ml}$ beaker. $5 \mathrm{~g}$ urea, $0.5 \mathrm{~g}$ ammonium chloride and $0.5 \mathrm{~g}$ resorcinol were dissolved in the solution. The $\mathrm{pH}$ was adjusted to 3.5 by adding of a $\mathrm{NaOH}$ solution. Then $90 \mathrm{ml}$ EPA was added into solution. The solution was agitated with emulsification isotropic machine to form oil/water emulsion. Then beaker suspended in a temperature-controlled water bath was agitated slowly with a digital mixer (IKA RW20, Eurostar). 
Last, $12.67 \mathrm{~g}$ of $37 \mathrm{wt} \%$ aqueous solution of formaldehyde was added into solution, and was heated to $55^{\circ} \mathrm{C}$ at a rate of $1{ }^{\circ} \mathrm{C} / \mathrm{min}$. After 4 hours heating, microcapsules were rinsed with deionized water, and then separated with a filter and air dried.

Characterization of microcapsule. Surface morphology of microcapsules were examined by field emission scanning electron microscopy (Nava650, FEI). Dried Microcapsules were mounted on conductive carbon tapes, sputtered with a thin layer of gold-palladium. Size distributions of microcapsules were determined by the particle size analyzer (MS3000, Malvern). Thermogravimetric analysis (Q600, TA) was performed using a nitrogen atmosphere and a heating rate of $10^{\circ} \mathrm{C} / \mathrm{min}$. Fourier-transform infrared (FTIR) spectra were obtained using a FTIR spectrometer (EQUINOX55, Bruker) to identify the chemical structure of microcapsules, which were prepared by grinding the sample with $\mathrm{KBr}$ or by attaching sample to a $\mathrm{KBr}$ disc.

Fracture experiment. Using the protocol established by White [9], healing performance is measured by fracture toughness of taper double-cantilever beam (TDCB) epoxy resin specimens. Microcapsules filled with EPA were stirred into the epoxy resin at various concentrations by weight, then mixed with DETA at a 100:12 parts per hundred of WSR618: DETA. The mixtures were degassed, poured into molds, and underwent $24 \mathrm{~h}$ at room temperature, followed by $24 \mathrm{~h}$ at $35^{\circ} \mathrm{C}$. Then specimens were precracked with a razor blade, and then pin-loaded on the bose 3100 under displace control at a rate of $5 \mu \mathrm{m} / \mathrm{s}$. After fractured, specimens were healed for $24 \mathrm{~h}$ at room temperature. The healed TDCB specimens were again loaded in a similar manner.

\section{Results and discussion}

Surface morphology and size distribution. Surface morphology of microcapsule were analyzed by SEM, as shown in Fig. 1(a). The capsules have a rough outer surface and a smooth non-porous inner shell wall. This inner surface is believed to be the result of the deposition of low molecular weight UF pre-polymer at the oil-water interface [8]. It can provide microcapsules long shelf-life and excellent permeability. The rough outer surface is formed as UF nanoparticles deposited along the interface. The microcapsule size is in a wide range of 20-480 mm, as shown in Fig. 1(b). The reason for this is that the fluid flow around the propeller is turbulent, which result in a wider length scale. In this study, the average diameter of the prepared microcapsules is $155 \mu \mathrm{m}$, which is proper for self-healing application.

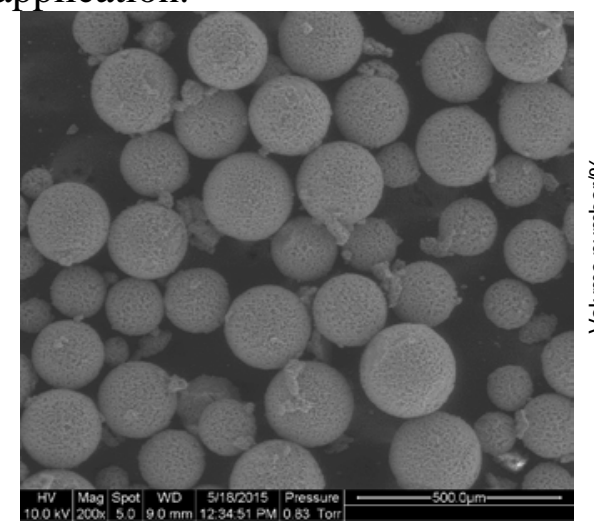

(a)

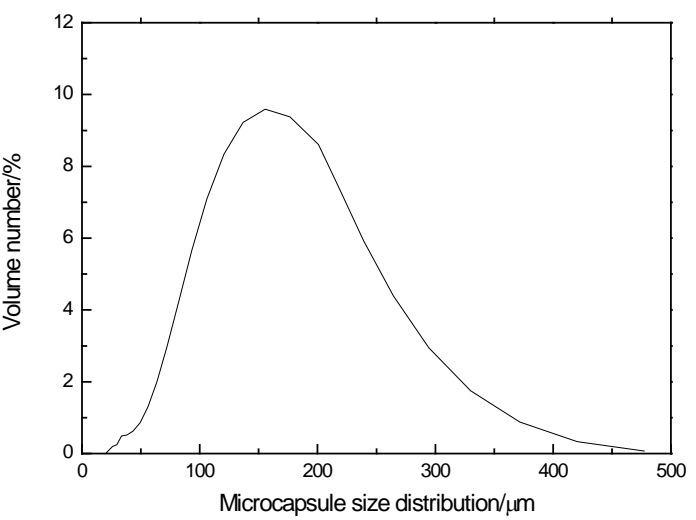

(b)

Fig. 1 (a) Surface morphology and (b) size distributions of microcapsules

Chemical structure. Fig. 2 shows the FTIR spectra of UF wall shell material, core material EPA and microcapsules. The FTIR spectrum of UF wall shell material displays an O-H stretching vibration peak at $3424 \mathrm{~cm}^{-1}$, C-N stretching vibration peak at $1544 \mathrm{~cm}^{-1}$. This confirms that the shell material is made of urea-formaldehyde polymer. Obviously, the FTIR spectrum of UF microcapsules containing EPA is closely matching with the characteristic peak of EPA for C-H stretching vibration peak at $2981 \mathrm{~cm}^{-1}$, absorption peak of $\mathrm{C}=0$ at $1740 \mathrm{~cm}^{-1}$, and $\mathrm{C}-\mathrm{O}-\mathrm{C}$ at $1159 \mathrm{~cm}^{-1}, 1030 \mathrm{~cm}^{-1}$, indicating that the UF microcapsules are filled with EPA. 


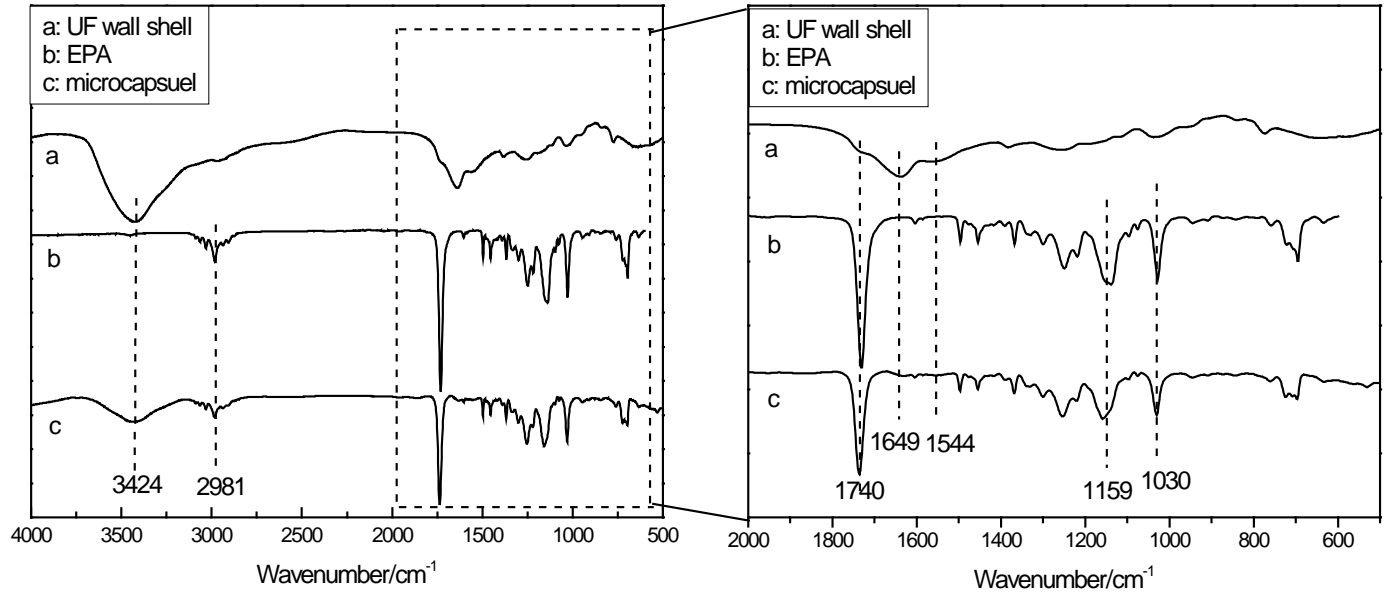

Fig. 2 Chemical structure of microcapsules

Thermal Analysis. The storage stability is important for the applications of microcapsules. Their storage stability was characterized by thermogravimetric analysis (TGA), as shown in Fig. 3. The weight loss of EPA between 50 and $200{ }^{\circ} \mathrm{C}$ is due to evaporation. Due to formation higher thermal stability of cross-linked UF polymer, the weight loss of microcapsule is in range of $120-300^{\circ} \mathrm{C}$. The weight loss of microcapsules on TGA curves below $200{ }^{\circ} \mathrm{C}$ is mainly due to the diffusion of EPA. When the temperature is approximately up to $200{ }^{\circ} \mathrm{C}$, the wall material begins to decompose. The weight loss of microcapsule is less than $10 \%$ below $147^{\circ} \mathrm{C}$, suggesting that the microcapsules have a good thermal stability.

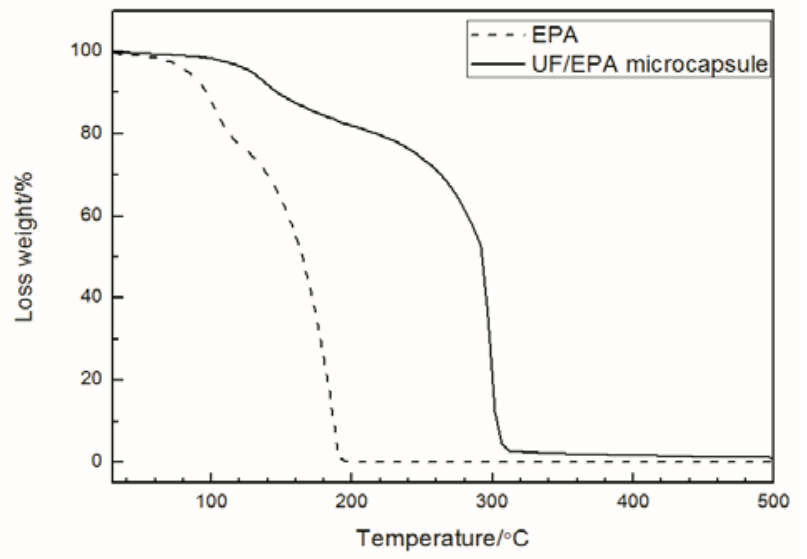

Fig. 3 Weight loss of EPA and UF microcapsule filled with EPA

Self-healing performance. Solvent was used to heal crack of thermoplastic polymers and the healing mechanism involves solvent-induced swelling and polymeric chain entanglement [10]. The crack healing of solvent is confirmed by manually induced healing test, and healing efficiency is 90.9\% as shown in Fig. 4(a). The microcapsule concentration has obvious effect on healing load and healing efficiency. When microcapsule concentration is $1 \%$, healing efficiency appears at $47 \%$. When the concentration is $5 \%$, healing efficiencies can be up to about $98 \%$. This shows that the fracture toughness of the materials can be fully restored to its original situation. While the concentration increases to $10 \%$, the healing efficiency decreases to $89 \%$, that is to say that excessive microcapsules do not further improve healing efficiency. Microcapsules can be raptured by crack, conformed by Fig. 4(b). Then solvents were released to crack region and bonded the crack, suggested by region of healed film. 


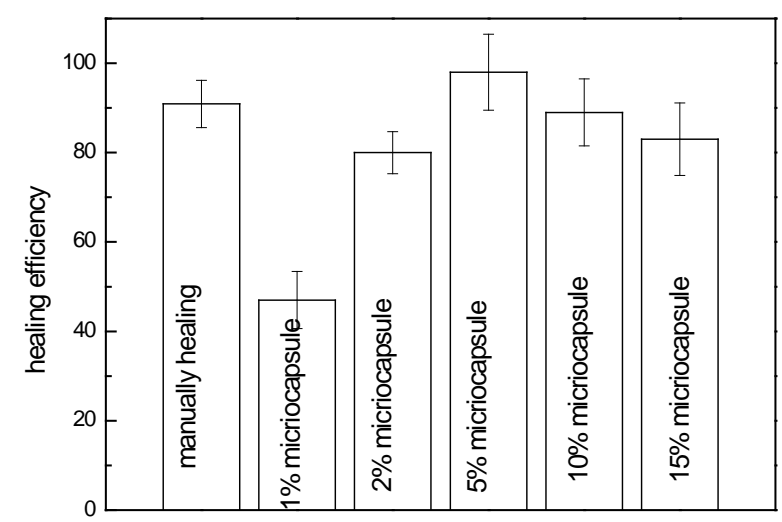

(a)

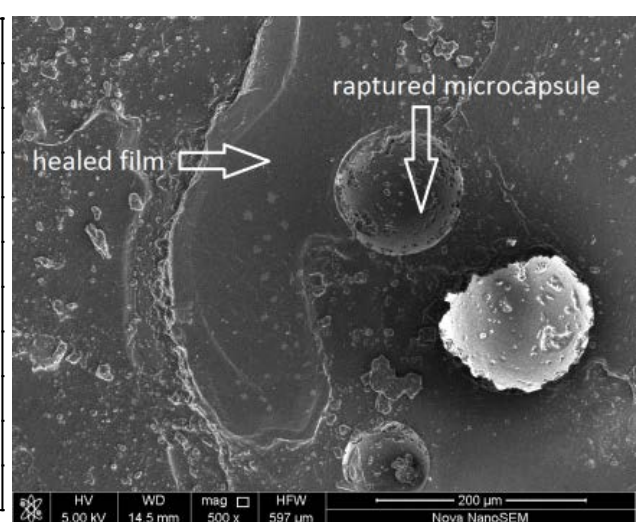

(b)

Fig. 4 Self-healing performance of microcapsule/epoxy resin composite.(a)self-healing efficiency with various microcapsule concentration; (b)surface morphology of crack plane

\section{Conclusion}

UF microcapsules filled with EPA were prepared by in situ polymerization in an oil/water emulsion. The surface morphology of microcapsules had a rough outer surface and a smooth non-porous inner shell wall. And the average diameter of microcapsules was $155 \mu \mathrm{m}$. Microcapsules had a good thermal stability, and the weight loss was less than $10 \%$ below $147^{\circ} \mathrm{C}$. Self-healing epoxy resins were achieved by incorporating EPA microcapsule. The in situ efficiency was dependent on microcapsule concentration. When the concentration was $5 \%$, fracture toughness of composites could be fully restored to its original situation.

\section{References}

[1] S.R. White, N.R. Sottos, P.H. Geubelle, J.S. Moore, M.R. Kessler, S.R. Sriram, E.N. Brown, S. Viswanathan, Autonomic healing of polymer composites, Nature 409 (2001) 794-797.

[2] J.D. Rule, E.N. Brown, N.R. Sottos, S.R. White, J.S. Moore, Wax-Protected Catalyst Microspheres for Efficient Self-Healing Materials, Adv. Mater. 17 (2005) 205-208.

[3] Y.C. Yuan, M.Z. Rong, M.Q. Zhang, J. Chen, G.C. Yang, X.M. Li, Self-healing polymeric materials using epoxy/mercaptan as the healant, Macromolecules 41 (2008) 5197-5202.

[4] X.J. Ye, J.L. Zhang, Y. Zhu, et al., Ultrafast self-healing of polymer toward strength restoration, Acs. Appl. Mater. Inter. 6 (2014) 3661-3670.

[5] M.M. Caruso, D.A. Delafuente, V. Ho, N.R. Sottos, J.S. Moore, S.R. White, Solvent-promoted self-healing epoxy materials, Macromolecules 40 (2007) 8830-8832.

[6] M.M. Caruso, B.J. Blaiszik, S.R. White, N.R. Sottos, J.S. Moore, Full Recovery of Fracture Toughness Using a Nontoxic Solvent - Based Self - Healing System, Adv. Funct. Mater. 18 (2008) 1898-1904.

[7] B.J. Blaiszik, M.M. Caruso, D.A. McIlroy, J.S. Moore, S.R. White, N.R. Sottos, Microcapsules filled with reactive solutions for self-healing materials, Polymer 50 (2009) 990-997.

[8] E.N. Brown, M.R. Kessler, N.R. Sottos, S.R. White, In situ poly(urea-formaldehyde) microencapsulation of dicyclopentadiene, J. Microencapsul. 20 (2003) 719-730.

[9] E.N. Brown, N.R. Sottos, S.R. White, Fracture testing of a self-healing polymer composite, Exp. Mech. 42 (2002) 372-379.

[10] S. Neuser, V. Michaud, S.R. White, Improving solvent-based self-healing materials through shape memory alloys, Polymer 53 (2012) 370-378. 